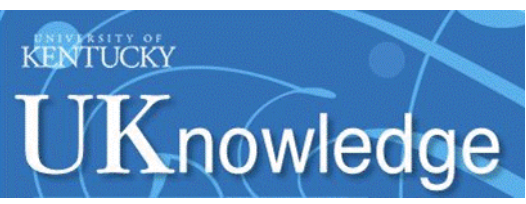

University of Kentucky

UKnowledge

\title{
Understanding the Influence of Stigma and Discrimination for the Functional Limitation Severity - Psychological Distress Relationship: A Stress and Coping Perspective
}

Robyn Lewis Brown

University of Kentucky, Robyn.Brown@uky.edu

Follow this and additional works at: https://uknowledge.uky.edu/sociology_facpub

Part of the Mental and Social Health Commons, and the Sociology Commons

Right click to open a feedback form in a new tab to let us know how this document benefits you.

\section{Repository Citation}

Brown, Robyn Lewis, "Understanding the Influence of Stigma and Discrimination for the Functional Limitation Severity - Psychological Distress Relationship: A Stress and Coping Perspective" (2017). Sociology Faculty Publications. 12. https://uknowledge.uky.edu/sociology_facpub/12

This Article is brought to you for free and open access by the Sociology at UKnowledge. It has been accepted for inclusion in Sociology Faculty Publications by an authorized administrator of UKnowledge. For more information, please contact UKnowledge@lsv.uky.edu. 


\section{Understanding the Influence of Stigma and Discrimination for the Functional Limitation Severity - Psychological Distress Relationship: A Stress and Coping Perspective}

Digital Object Identifier (DOI)

https://doi.org/10.1016/j.ssresearch.2016.08.002

Notes/Citation Information

Published in Social Science Research, v. 62, p. 150-160.

(C) 2016 Elsevier Inc. All rights reserved.

This manuscript version is made available under the CC-BY-NC-ND 4.0 license https://creativecommons.org/licenses/by-nc-nd/4.0/.

The document available for download is the author's post-peer-review final draft of the article. 


\title{
UNDERSTANDING THE INFLUENCE OF STIGMA AND DISCRIMINATION FOR THE FUNCTIONAL LIMITATION SEVERITY - PSYCHOLOGICAL DISTRESS RELATIONSHIP: A STRESS AND COPING PERSPECTIVE*
}

\author{
Robyn Lewis Brown \\ Department of Sociology, University of Kentucky
}

\section{INTRODUCTION}

Functional limitations - defined as restrictions in carrying out activities of daily living (ADLs), instrumental activities (IADLs), or more complex work and social activities (Stuck et al., 1999) - affect a considerable portion of the U.S. population. Although prevalence rates vary depending upon the definition of functional limitation applied, the U.S. Census estimates that 56.7 million people - or nearly one-fifth of the population - experience some degree of functional limitation, and 38.3 million people (12.6 percent of the population) experience severe limitations (Brault, 2012).

Estimates of functional limitation in the population raise concern because it is associated with a host of secondary physical and mental health complaints, the most prevalent of which is depressive symptoms (Hughes, Swedlund, Petersun \& Nosek, 2001; Nosek \& Hughes, 2003). Indeed, a greater degree of functional limitation is associated with higher levels of depressive symptoms both cross-sectionally and over time (Breslin et al., 2006; Turner \& Noh, 1988; Yang, 2006). This pattern of findings is found across both self-report and clinical measures of functional limitation and depressive symptoms (Bruce, 2001), and has spurred interest in the question of what social or psychological risk factors link variation in functional limitation severity with psychological distress.

Most social science-oriented studies of the functional limitation severity-depressive symptoms association have drawn from a stress and coping framework (Lazarus \& Folkman, 1984; Pearlin, 1989; Pearlin et al., 1981) to investigate stressors such as major life events and chronic strains and psychosocial coping resources such as mastery, self-esteem and perceived social support as explanations (Bruce, 2001; Turner \& Noh, 1988; Yang, 2006). In this work - and perhaps because a substantial portion of the effect of functional limitation severity on depressive symptoms is not explained by these factors (Yang, 2006) - it is often

\footnotetext{
*Address correspondence to: Robyn Lewis Brown, Assistant Professor, Department of Sociology, University of Kentucky, 1529 Patterson Office Tower, Lexington, KY 40506; robyn.brown@uky.edu.

Publisher's Disclaimer: This is a PDF file of an unedited manuscript that has been accepted for publication. As a service to our customers we are providing this early version of the manuscript. The manuscript will undergo copyediting, typesetting, and review of the resulting proof before it is published in its final citable form. Please note that during the production process errors may be discovered which could affect the content, and all legal disclaimers that apply to the journal pertain.
} 
acknowledged that adaptation to stressful circumstances can be more difficult for people with functional limitations because of the unique social and personal challenges they experience (e.g., Turner \& Noh, 1988). However, the form and meaning of these challenges are not clearly articulated in this literature. Additionally, the tendency in this research of categorically comparing people with functional limitations to the general population raises concern that important sources of variation among people with functional limitations may be obscured (Brown, 2015; Miller \& Major, 2000). An alternative approach limited to people with functional limitations could further detail, for example, the extent to which the psychological effects of limitation severity are accounted for by various dimensions of stress exposure and the availability of coping resources.

Addressing these considerations, the current study draws on a minority stress perspective (Meyer 2003) and the largely qualitative body of research on physical health-related stigma and discrimination (Crocker \& Quinn, 2000; Miller \& Major, 2000; Susman, 1994; Thorne \& Paterson, 1998) to explore the salience of social devaluation for the relationship between functional limitation severity and psychological distress within a stress and coping framework. Its goal is to highlight that people who occupy disadvantaged social statuses are potentially host to a variety of negative interactions and events not experienced by those who do not occupy such statuses. In the absence of a conceptual scheme that includes such indicators of social disadvantage along with more typically-assessed forms of stressor exposure such as major life events and chronic strains, the ability to examine the relative effects of various sources of strain and coping responses may be compromised.

Toward this end, this study draws on two waves of data from a community survey of adults with chronic health conditions in Miami-Dade County, Florida, to assess the relative significance of perceived stigma and the experience of discrimination, along with four additional forms of stressor exposure (bodily pain, major life events, recent life events and chronic strains), and the coping resources of social support, mastery and self-esteem for the functional limitation severity-depressive symptoms association.

\section{A Stress and Coping Perspective}

Stress and coping models recognize that multiple processes link stressor exposure and the availability of psychosocial coping resources with health outcomes (Lazarus \& Folkman, 1984; Pearlin, 1989). Two processes linking functional limitation severity and depressive symptoms are further elaborated upon in this study. First, functional limitation is described as a source of enduring or chronic strain in the stress and coping literature, in part, because greater limitation can make the resolution of other stressful experiences more difficult (Brown, 2010; Brown \& Turner, 2012; Turner \& Noh, 1988; Yang, 2006). This observation is consistent with the concept of stress proliferation, or the phenomenon by which one stressful experience gives rise to a host of secondary stressors (Pearlin, 1989; Pearlin et al., 2005), and supports the possibility that functional limitation severity may indirectly influence depressive symptoms, in part, through its association with other stressors. Greater functional limitation is additionally thought to influence coping resources - and, as a consequence, psychological well-being - in the extent to which it challenges one's ability to direct and regulate one's life circumstances and social relationships (Bruce, 2001). This 
possibility alludes to the salience of psychosocial coping resources such as perceived social support, mastery and self-esteem for the functional limitation severity-depressive symptoms association.

\section{Stigma, Discrimination and Other Stressors}

The damaging effects of stressor exposure for mental health among people with physical health issues have become increasingly apparent from studies that have included multiple dimensions of stressor exposure, including major and recent life events, discriminatory events, and chronic strains (Bruce, 2001; Nosek, Hughes, \& Robinson-Whelan, 2008; Turner $\&$ Noh, 1988). Although less attention has been paid to the question of whether such stressors help explain the mental health effects of functional limitation severity, evidence that greater limitation is linked with a greater occurrence of major and potentially traumatic life events and chronic strains (Bruce, 2001; Nosek et al., 2008; Turner \& Noh, 1988) provides some support for this possibility.

With respect to the dimensions of stressor exposure assessed in this investigation, the effects of social stressors associated with impaired physical functioning are of particular interest. Such stressors are referred to as minority stressors because they are more common or unique to people who occupy disadvantaged statuses and may require greater adaptation than what is required of people who do not occupy such statuses (Meyer, 2003; Meyer, Schwartz \& Frost, 2008; Pearlin, 1999). Minority stressors include discrete experiences of discrimination, ranging from major events such as being denied a job or housing as well as everyday slights such as receiving worse service at restaurants or stores than others, and one's ongoing awareness of social devaluation or the potential for negative treatment (henceforth referred to as perceived stigma) (Corrigan \& Watson, 2002; Meyer, 2003; Stuber, Meyer \& Link, 2008).

Goffman (1963) long ago noted that, among people with physical impairments, the experience of social devaluation can challenge one's fundamental sense of value and worth. Subsequent research has shown that, although not all people with physical limitations experience discrimination or feel stigmatized (Joachim \& Acorn, 2000; Miller \& Major, 2000), these considerations remain relevant. For example, a recent field experiment on employee hiring behavior found clear evidence of disability discrimination in expressions of employer interest (Ameri et al., 2015), and public opinion research finds that 65 percent of those surveyed in a national poll believe there is some or a lot of prejudice and discrimination against people with physical disabilities (Kaiser Public Opinion Spotlights, 2004). Both perceived stigma and experiences of major and day-to-day discrimination are also linked with depressive symptoms among people with functional limitations (Brown, 2014; Crocker \& Quinn, 2000; Susman, 1994; Thorne \& Paterson, 1998). Although depressive symptoms also appear to exacerbate feelings of social devaluation, it is notable that perceived stigma and discrimination are found to exert effects on depressive symptoms when the reciprocal effects of depressive symptoms are accounted for (Livingston \& Boyd, 2010; Markowitz 1998).

There is also some support for considering perceived stigma and discrimination as mediators of the functional limitation severity—depressive symptoms association. Several qualitative 
studies, for instance, describe how the severity of one's limitation can change the nature of social interactions, resulting in greater feelings of devaluation and lower well-being among those with more serious limitations (Cahill \& Eggleston, 1995; Karp, 1999). Prior work also indicates that perceived stigma and discriminatory experiences are linked empirically (Darling \& Heckert, 2010; Stuber et al., 2008), and several stigma researchers contend that perceived stigma is predicated on one's awareness of prejudice and experiences of discrimination (e.g., Corrigan \& Rao, 2012; Sirey et al., 2001). For this reason, perceived stigma and discrimination are included as correlated predictors in the present study.

\section{Psychosocial Coping Resources}

With respect to the coping resources included in this analysis, stress researchers have identified perceived social support, mastery and self-esteem as resources that are particularly influential in the prediction of depressive symptoms among people with functional limitations (Bruce, 2001; Taylor \& Lynch, 2004; Turner \& Noh, 1988; Yang, 2006). Perceived social support refers to one's level of certainty that he or she is loved, valued and cared for by significant others (Cobb, 1976). Functional limitation is associated with lower social support and a decline in social support over time, which diminishes psychological well-being (Miech \& Shanahan, 2000; Turner \& Brown, 2010; Warner \& Adams, 2012). The challenges of maintaining supportive social ties are illustrated by research documenting that greater functional limitation can make it difficult to engage in more high-demand social activities (Everard et al., 2000) or emotionally-intimate relationships (Seeman et al, 1995). Although clear associations are observed between functional limitation and social support, and social support and depressive symptoms, respectively, the mediating role of social support for the functional limitation severity-depressive symptoms association may be modest. For example, a community study of North Carolina residents finds that having a confidant and being satisfied with one's social interactions do not account for the association between functional decline and depressive symptoms over a six-year period (Yang, 2006). This conclusion may be limited, however, by the indices of social support utilized, which are measures of received support. Other research indicates that the mental health benefits of social support are most evident in studies of perceived social support (for a review, see Turner \& Brown, 2010), which is assessed in the current investigation.

Similar to its impact on social resources, functional limitation is also thought to reduce psychological well-being by diminishing psychological coping resources such as mastery which refers to a sense of personal control (Pearlin \& Schooler, 1978) - and self-esteem, which refers to a positive sense of self-worth (Rosenberg, 1986). Each of these resources is associated with a decline in depressive symptoms over time (Bruce, 2001; Taylor \& Lynch, 2004; Turner \& Noh, 1988; Yang, 2006). However, people with greater functional limitation report less control over their life circumstances and environment (Turner \& Noh, 1988; Yang, 2006). Greater limitation and increases in limitation are also found to diminish selfesteem (Reitzes \& Mutran, 2006; Orth et al., 2010); as an illustration, one participant in a qualitative study of women with chronic physical disabilities noted, "It's a constant struggle with your self-esteem and with your feelings of who you are" (Zitzelsberger, 2010, p. 395). It is, thus, perhaps unsurprising that mastery and self-esteem are each found to partly mediate the association between increases in functional limitation and increases in 
depressive symptoms over time. It should be noted, however, that prior studies indicate that the effect of limitation on depressive symptoms remains robust in models accounting for the mediating effects of these coping resources (Thoits, 2011; Yang, 2006).

\section{Goals of the Present Study}

In summary, prior research provides grounds for anticipating that perceived stigma and experiences of discrimination, along with other stressors and the availability of psychosocial coping resources, may help account for the association between functional limitation severity and depressive symptoms (Bruce, 2001; Cahill \& Eggleston, 1995; Nosek et al., 2008; Turner \& Noh, 1988; Yang, 2006). To explore this possibility, the present study tests four hypotheses:

(1) Hypothesis 1: Functional limitation is associated with depressive symptoms over the three-year study period.

(2) Hypothesis 2: Variation in depressive symptoms across the study waves is influenced by perceived stigma and discrimination, along with other stressors. Specifically, perceived stigma, major and day-to-day discrimination, major life events, recent life events, chronic strains and bodily pain are associated with increases in depressive symptoms.

(3) Hypothesis 3: The psychosocial coping resources of social support, mastery and self-esteem are associated with decreases in depressive symptoms across the study waves.

(3) Hypothesis 4: The association between functional limitation severity and increases in depressive symptoms is substantially mediated by one's exposure to social stressors (i.e., perceived stigma, major and day-to-day discrimination, major life events, recent life events and chronic strains) and the availability of coping resources (i.e., social support, mastery, and self-esteem).

The evaluation of these hypotheses controls for age, gender, socioeconomic status, and race/ ethnicity, which are linked with psychological well-being among people with functional limitations. Specifically, age and socioeconomic status are found to be inversely associated with depressive symptoms among people with functional limitaitons (Bruce, 2001; Yang, 2006), women with functional limitations are found to report higher levels of depressive symptoms than their male counterparts (Brown, 2014; Coyle \& Roberge, 1992), and there is some evidence that Latinos with functional limitations report higher levels of depressive symptoms than non-Hispanic Whites and African Americans with disabilities (Brown \& Turner, 2010).

\section{METHODS}

\section{Data}

Data are derived from a two-wave panel study of Miami-Dade County, Florida, residents that was undertaken in order to examine the social determinants of mental health problems among people with and without chronic physical health conditions. Based on national age, gender, and race/ethnicity-specific rates of disability, and on the Miami-Dade County 
demographic structure, approximately 10,000 households were randomly screened to develop a sampling frame within which people with physical disabilities were significantly overrepresented (Turner, Lloyd \& Taylor, 2006). Stratified random samples were drawn so that women and men were equally represented within the study, and so that the racial/ethnic composition of study participants would reflect that of the Miami-Dade County community. Additional details regarding the sampling procedure are presented by Turner, Lloyd and Taylor (2006).

First-wave interviews were completed from 2000 to 2001, with a success rate of 82 percent. Interviews were administered by well-trained and predominantly bilingual interviewers using computerized questionnaires in either English or Spanish, as preferred by each participant. Included in the study were 559 people who confirmed the presence of a physically-disabling health condition within the first interview. Respondents were reinterviewed three years later. The second wave of interviews achieved a success rate of $74.5 \%$ among the subsample of people with chronic health conditions. The working sample for this study includes the 417 respondents who confirmed that they experience a physicallydisabling health condition and provided complete responses during both interviews.

Excluding are the $100 \mathrm{~W} 1$ participants who died in the interim and $42 \mathrm{~W} 1$ participants who were too ill to be interviewed. A comparison between those respondents who completed both interviews and all others regardless of reason for exclusion revealed several small but statistically significant differences. Cases lost to W2 interviews previously reported lower levels of social stress, socioeconomic status (SES), and pain, and slightly higher levels of functional limitations and depressive symptoms. The magnitude of these differences varied from 0.10 to .30 standard deviations. It should be noted, however, that a consistent pattern of findings is observed among the subsample included in this report and the full sample at baseline.

Because this is a sample of people with chronic health conditions, it includes a greater proportion of older respondents than what is observed in the general population. Ages in the sample range from 20 to 93 with a median of 59, whereas the median age of the general population of Miami-Dade County in 2000 was 35.6 according to the U.S. Census Bureau. Given this discrepancy in ages, it is inaccurate to suggest that this sample is representative of the Miami-Dade County population. However, the sample is generally representative of people with chronic health conditions in Miami-Dade County. Also, because this sample was drawn to broadly represent people with physical disabilities in this community, it is heterogeneous with respect to the types of health conditions reported and their age of onset. A limitation of this sampling approach is that individual categories of health conditions include too few cases to examine variation by health condition. The distribution of primary conditions giving rise to physical disability reported during the initial interview is presented as Table 1 . The mean age of onset of a health condition reported during the first interview is 45 , though the sample includes people with congenital conditions and those whose conditions occurred after age 80 . Despite this variation, a consistent pattern of findings is observed in sub-group analyses by age of onset and Wald tests demonstrate that age of onset does not significantly improve model fit. For these reasons, age of onset is not included as a predictor in the analyses to be presented. 


\section{Measures}

Summary statistics for all study variables are found in Table 2 .

\section{Depressive symptoms}

The outcome variable, depressive symptoms, is assessed at W2, with W1 levels controlled in the analyses to assess changes in symptoms across the two waves of data. Depressive symptoms are estimated using a modified version of the 20-item Center for Epidemiological Studies Depression Scale (CES-D) (Radloff, 1977), for which there is ample evidence of reliability and validity. This abbreviated 14-item measure excludes somatic complaints in order to avoid potential confounding of mental and physical health status. The omitted items include problems with eating, keeping your mind on what you are doing, effort, restlessness, talking, and getting going. The summated measure has high reliability (W1 $a=.83$; W2 $a=$. 89) and produces results similar to the full scale.

\section{Independent variables}

Included as independent variables are level of functional limitation, perceived stigma, major and day-to-day discrimination, major and recent life events, chronic strains, social support, mastery and self-esteem, as indexed at W1.

The measure of functional limitation, introduced by Turner and colleagues (Gayman, Turner \& Cui. 2008; Brown \& Turner, 2010), is based on the models of disability proposed by the World Health Organization (2001). The measure combines indicators of physical mobility, instrumental daily activities, and basic activities of daily living, an approach which provides a relatively comprehensive picture of functional abilities and limitations across the spectrum of physical functioning. Pooling from several previously-employed measures (see Gayman et al., 2008, for a complete list), this standardized measure $(\alpha=.91)$ is based on 19 questions gauging level of functional limitation, ranging from not at all (1) to completely (5).

Perceived stigma is assessed by a seven-item index $(a=.91)$ drawn from the summed responses (i.e., never, rarely, sometimes, often, always) to seven statements: (1) "People stare at you because of your physical limitation;" (2) "People avoid close contact with you because of your physical limitation;" (3) "Your physical appearance makes you feel embarrassed or ashamed;" (4) "People act as if your physical limitation is somehow your fault;" (5) "People act as if having a physical limitation is a sign of personal weakness;" (6) "Your physical limitation makes you feel different from other people;" and (7) "Some people make rude comments or are insensitive about your physical limitation." The questions used to construct this index are derived from existing perceived stigma indices (i.e., Jacoby, 1994; Link et al., 1989) and were refined in focus groups conducted among people with physical disabilities. Factor analysis reveals that these items load on a single factor, supporting their inclusion as one index (Brown, 2014).

Three additional dimensions of stressor exposure are considered: Major and day-to-day discrimination are measured with Williams and colleagues' (1997) inventories (8 items each), which consider major experiences of unfair treatment, such as being fired or denied 
housing, as well as more routine or relatively minor experiences, such as being treated with less courtesy than others or being insulted. While these measures were developed to index race/ethnicity-based discrimination, they have subsequently been used as general discrimination inventories, as utilized here. Major and recent life events (41 items and 32 items, respectively) are indexed with Turner and Avison's (2003) measure, which includes experiences with major but not violent stressors (e.g., parental divorce, failing a grade in school), life traumas (e.g., rape, physical and emotional abuse), witnessing violence, receiving bad news, and the death of relatives or close friends. Chronic strains are measured with a 39-item index adapted from Wheaton's (1994) inventory, modified to better capture enduring stressors older adults are likely to experience. The items fall into seven categories: General or ambient problems, work/employment, relationships, parenting, family, social life and recreation, and health concerns. Consistent with common practice, each score is a straight count of the number of stressors reported.

Assessment of social support is based upon the widely-used Provisions of Social Relations Scale, for which evidence of both reliability and construct validity is available (Turner \& Noh, 1988). Participants were asked to indicate whether each of eight statements about support from friends and each of eight statements about support from family were very true; moderately true; somewhat true; or not at all true (such as knowing your friends/family will always be there; feeling very close to your friends/family; and feeling your friends/family really care about you). The index is a sum of these 16 items $(\alpha=.91)$.

Mastery is measured with the seven-item scale developed by Pearlin and Schooler (1978). The index is a summed index $(a=.78)$ assessing the extent to which respondents feel they have control over the things that happen in their lives; are able to solve problems; can change important aspects of their lives; feel helpless (reversed); feel pushed around (reversed); are responsible for what happens in their future; and can do anything they set their mind to. Responses to each item range from strongly disagree (1) to strongly agree (5). Self-esteem is indexed with a shortened version $(\alpha=.70)$ of Rosenberg's (1986) measure drawn from six items concerning whether respondents feel they have a number of good qualities; are a person of worth at least equal to others; are able to do things as well as most other people; have a positive self-attitude; are satisfied with themselves; and are inclined to feel they are a failure (reverse coded). Responses to each item range from strongly disagree (1) to strongly agree (5).

\section{Covariates}

All analyses control for gender, age, race/ethnicity, and socioeconomic status, as indexed at W1. Gender is coded 1 for females and 0 for males. Age is employed as a continuous measure in years. Race/ethnicity is a set of dummy variables including non-Hispanic Whites $(\mathrm{n}=98)$, African Americans ( $\mathrm{n}=164)$, Cubans $(\mathrm{n}=88)$, and non-Cuban Hispanics $(\mathrm{n}=67)$. The "non-Cuban Hispanic" designation primarily represents individuals from Central America. In all regression analyses, non-Hispanic Whites will represent the reference category. Socioeconomic status is estimated in terms of three components-income, education and occupational prestige level (Hollingshead, 1957). Income was assessed before taxes, ranging from 0 to more than $\$ 135,000$ (mean $=\$ 15,000-\$ 19,999$ ). Education was measured in years, 
ranging from 0 to 20-plus (mean=11.04). Occupational prestige level is based on NamPowers Occupational Status Scores, which considers occupations held the longest (Nam \& Powers, 1983). The composite socioeconomic status measure was selected because information on household income could not be obtained for 15 percent of the sample. Scores on these three dimensions are standardized, summed, and divided by the number of measures on which each respondent provided data.

\section{Statistical analysis}

After examining bivariate correlations in order to assess the basic patterns of association among key study variables, a structural equation model (SEM) analysis was utilized to examine the extent to which changes in depressive symptoms from $\mathrm{W} 1$ to $\mathrm{W} 2$ are influenced by functional limitation severity, perceived stigma and other forms of stressor exposure, and the coping resources considered, net of the sociodemographic controls, as indexed at W1. The direct and indirect effects of functional limitation on changes in depressive symptoms were formally tested using the mediation procedures described by Muthén and Muthén (2010) for Mplus software, which apply the delta method of testing mediation.

\section{RESULTS}

Table 3 presents the inter-correlations of major study variables. It is noteworthy that every general component of the model is associated with depressive symptoms, and in the expected directions. Greater functional limitation, as well as several dimensions of stressor exposure - specifically, perceived stigma, major discrimination and chronic strains - are positively associated with greater depressive symptoms at W2, whereas higher levels of the social and personal resources considered are negatively associated with depressive symptoms. Consideration of the correlations between level of limitation and the hypothesized mediators also provides some preliminary support for the hypothesis that the association between level of limitation and depressive symptoms may derive from variation in perceived stigma, stressor exposure, and coping resources. Greater stigma is positively associated with functional limitation severity, though no other forms of stressor exposure are associated with level of limitation. Additionally, mastery and self-esteem are inversely associated with level of limitation.

The hypothesized associations between functional limitation severity, depressive symptoms, and the mediating variables are further elaborated upon in the SEM analysis. As a precursor to the full model, Preacher and Hayes (2007) emphasize the importance of first establishing a connection between that which is to be mediated and the outcome of interest, as presented in Figure 1. Estimation of this preliminary model, including only functional limitation, depressive symptoms and the sociodemographic controls, produces a just identified model and, as such, meaningful fit statistics are not provided. The standardized path coefficient from functional limitation to depressive symptoms provides clear support for Hypothesis 1 by demonstrating that greater limitation is associated with increases in depressive symptoms over the study period, net of the controls $(\beta=.129, p<.01)$.

With the addition of perceived stigma, other sources of stressor exposure, and coping resources, as illustrated in Figure 2, the model remains just-identified. This prevents 
examination of whether a model allowing the discrimination and stigma measures to correlate significantly improves model fit. However, these correlations are retained because of their theoretical linkages. When the combined effects of limitation, perceived stigma, other stressor exposure, and coping resources are considered, the coefficient for the path from level of limitation to W2 depressive symptoms no longer approaches significance. However, perceived stigma, chronic strains, social support, mastery and self-esteem are found to predict changes in depressive symptoms over the two waves of data. This pattern is partly consistent with the prediction of Hypothesis 2 and Hypothesis 3, that various sources of strain and the availability of coping resources will influence changes over time in depressive symptoms. The standardized coefficients indicate that social support exerts the strongest influence on changes in depressive symptoms. Hypothesis 4 predicted that the stressors and resources assessed would mediate the association between functional limitation severity and increases in depressive symptoms Supporting this hypothesis, the reduction in the coefficient for level of limitation from the preliminary model (from .129 to .011) indicates that a substantial part of the association between functional limitation and depressive symptoms is explained by the mediating factors assessed. Mediation tests reveal that greater perceived stigma and chronic strains account for a substantial portion of this effect - about 86 percent. The total effect of changes in limitation on depressive symptoms is .080. The indirect effect of perceived stigma (.053) accounts for 77 percent of the mediating effect observed and about 66 percent of the total effect of functional limitation severity. The indirect effect of chronic strains (.016) accounts for 23 percent of the mediating effect and 20 percent of the total effect of functional limitation.

It should be noted that earlier work (e.g., Yang, 2006) indicating that mastery and selfesteem partly explain the association between functional limitation and increases in depressive symptoms was replicated with the present data with a model not controlling for the effects of perceived stigma or discrimination. However, when these stressors are included in the model, neither mastery nor self-esteem significantly mediates the effects of level of limitation on depressive symptoms. Additional tests considering the mediating role of major life events, recent life events and chronic strains in a model not including the perceived stigma and discrimination measures yielded a pattern of findings consistent with those reported in Figure 2.

It also seemed plausible that the connection between functional limitation severity and depressive symptoms might derive from physical rather than contextual or psychosocial strains that accompany limitation. Bodily pain, for example, is considered an obstacle to one's ability or motivation to engage in activities conducive to well-being (Gayman, Brown \& Cui, 2011), and it is associated with depressive symptoms among people with functional limitations (Baune et al., 2008; Gayman et al., 2011). Additional tests (not presented) assessing the mediating role of bodily pain using a multiplicative pain inventory (Gayman et al., 2011) found no support for its inclusion as a mediator of the functional limitation severity-depressive symptoms relationship. 


\section{DISCUSSION}

The basic premise of the present study is that a consideration of perceived stigma and discrimination within a more general stress and coping framework may provide a clearer understanding of variation in psychological distress associated with functional limitation severity. To this end, this study extends our understanding of the mental health effects of perceived stigma and discrimination, relative to and along with other forms of stressor exposure and the availability of psychosocial coping resources. It also demonstrates the utility of a stress and coping framework modified to include these stressors for understanding the functional limitation severity—depressive symptoms linkage.

Supporting prior research and Hypothesis 1, clear evidence of an association between functional limitation severity and depressive symptoms is observed in the baseline model. Hypothesis 2 and Hypothesis 3 further predicted that perceived stigma and discrimination, along with other stressors and the availability of coping resources, would contribute to variation over time in psychological distress among this sample of people with chronic health conditions. Partly supporting this prediction, perceived stigma is found to independently influence increases in depressive symptoms over the three-year study period. Increases in chronic strains, social support, mastery and self-esteem are also found to influence changes in depressive symptoms, with social support bearing the strongest influence. Contrary to expectations, major discrimination, day-to-day discrimination, major life events and recent life events are not independently associated with increases in depressive symptoms.

This investigation also examined the mechanisms through which functional limitation severity influences depressive symptoms over time, partly supporting Hypothesis 4 . Of the 86 percent of the effect of functional limitation severity explained by this analysis, perceived stigma explains 66 percent and chronic strains explain 20 percent. These findings lend support to research indicating that it is not necessarily the experience of functional limitation that matters for psychological well-being (Bruce, 2001; Turner \& Noh, 1988; Yang, 2006), further specifying that increases in depressive symptoms appear to largely derive from associated chronic stressors and higher levels of perceived stigma, in particular.

Indeed, the important linkages observed between functional limitation, perceived stigma and depressive symptoms highlight the need to further understand how functional limitation influences perceived stigma. Several possibilities suggested by prior research are that perceptions of stigma may vary depending upon the type of health condition involved, its duration and severity, and whether one's limitations are visible to others (Nosek \& Hughes, 2003; Rohmer \& Louvet, 2009). Because this sample was heterogeneous with respect to health conditions included, individual categories included too few cases to effectively examine these issues.

The central role perceived stigma plays in explaining the effects of functional limitation also suggests that prior research may overstate the significance of one's coping abilities in explaining the effects of functional limitation on psychological well-being. This is further supported in the present study's replication of prior research indicating that mastery and 
self-esteem partly explain the effect of functional limitation (Yang, 2006) in a model not controlling for the effects of perceived stigma and discrimination. This pattern of findings raises questions concerning the processes through which functional limitation may be linked with coping resources and perceived stigma. One potential explanation is that the extent to which functional limitation influences perceived stigma is dependent upon one's level of social support, mastery or self-esteem - possibilities recommended for future study.

Several limitations of the present study merit further comment. First, it is important to emphasize that the data employed in this study are from two waves of data collected three years apart and likely provide only a snapshot of the complex processes underlying variation in psychological distress among people with physical disabilities. Future research might consider how changes in functional limitation and the range of factors considered influence psychological distress across multiple points in time and perhaps situate our understanding of physical health-related stigma and discrimination within a life course framework. There is also a need to consider the potential for bi-directional relationships among the factors considered. Although recent study indicates that functional limitation predicts depressive symptoms whereas no evidence of a reverse association is found over a three-year period (Gayman et al., 2008), further consideration of the effects of depressive symptoms on perceived stigma and discrimination may ultimately broaden our understanding of their psychological consequences.

These limitations notwithstanding, this investigation highlights that assessing both healthrelated social stressors, such as stigma and discrimination, and more general stress processes helps clarify our understanding of the association between functional limitation severity and depressive symptoms. Further study is needed to determine whether these stressors offset the effects of other dimensions of stress exposure or coping responses (see also Hatzenbuehler, 2009) and the extent to which these stigma and discrimination influence the adverse outcomes often associated with other disadvantaged statuses (Meyer et al., 2008). However, the more general point for the field is that specific stress measures are needed to capture the variety of experience and social-structural realities of those who occupy disadvantaged social statuses.

\section{Acknowledgments}

This research is supported by a dissertation research grant from Florida State University awarded to Robyn Lewis Brown (2009-2010) and grants RO1 DA13292 and RO1 DA016429 from the National Institute of Drug Abuse to R. Jay Turner (r.jay.turner@vanderbilt.edu).

\section{References}

Baune BT, Caniato RN, Garcia-Alcaraz MA, Berger K. Combined effects of major depression, pain and somatic disorders on general functioning in the general adult population. Pain. 2008; 138(2): 310-317. [PubMed: 18258371]

Breslin FC, Gnam W, Franche R, Mustard C, Lin E. Depression and activity limitations. Social Psychiatry, Psychiatric Epidemiology. 2006; 41:648-655. [PubMed: 16721501]

Brown RL. Psychological distress and the intersection of gender and physical disability: Considering gender and disability-related risk factors. Sex Roles. 2014; 71(3-4):171-181. 
Brown RL. Functional limitation, pain and alcohol use: Exploring gender differences in the mediating role of depressive symptoms. Journal of Studies on Alcohol and Drugs. 2015; 76(5):809-817. [PubMed: 26402362]

Brown RL, Turner RJ. Physical disability and depression: Clarifying racial/ethnic contrasts. Journal of Aging and Health. 2010; 22:977-1000. [PubMed: 20194683]

Brown RL, Turner RJ. Physical limitation and anger: Assessing the role of stress exposure and psychosocial resources. Society and Mental Health. 2012; 2(2):69-84.

Bruce ML. Depression and disability in late life: directions for future research. The American Journal of Geriatric Psychiatry. 2001; 9(2):102-112. [PubMed: 11316615]

Cahill SE, Eggleston R. Reconsidering the stigma of physical disability. The Sociological Quarterly. 1995; 36(4):681-698.

Charmaz K. The self as habit: The reconstruction of self in chronic illness. OTJR: Occupation, Participation and Health. 2002; 22(1 suppl):31S-41S.

Cobb S. Social support as a moderator of life stress. Psychosomatic medicine. 1976; 38(5):300-314. [PubMed: 981490]

Corrigan PW, Rao D. On the self-stigma of mental illness: Stages, disclosure, and strategies for change. Canadian Journal of Psychiatry. Revue Canadienne de Psychiatrie. 2012; 57(8):464-469. [PubMed: 22854028]

Corrigan PW, Watson AC. The paradox of self-stigma and mental illness. Clinical Psychology: Science and Practice. 2002; 9(1):35-53.

Coyle CP, Roberge JJ. The psychometric properties of the Center for Epidemiological StudiesDepression Scale (CES-D) when used with adults with physical disabilities. Psychology and Health. 1992; 7(1):69-81.

Crocker, J., Quinn, DM. Social stigma and the self: Meanings, situations, and self-esteem. In: Heatherton, TF.Kleck, RE.Hebl, MR., Hull, JG., editors. The social psychology of stigma. New York: The Guilford Press; 2000. p. 153-183.

Darling RB, Heckert DA. Orientations toward disability: Differences over the lifecourse. International Journal of Disability, Development and Education. 2010; 57(2):131-43.

Earnshaw VA, Quinn DM. The impact of stigma in healthcare on people living with chronic illnesses. Journal of health psychology. 2012; 17:157-168. [PubMed: 21799078]

Everard KM, Lach HW, Fisher EB, Baum MC. Relationship of activity and social support to the functional health of older adults. The Journals of Gerontology Series B: Psychological Sciences and Social Sciences. 2000; 55(4):S208-S212.

Gayman MD, Brown RL, Cui M. Depressive symptoms and bodily pain: The role of physical disability and social stress. Stress \& Health. 2011; 27:52-63. [PubMed: 21359108]

Gayman MD, Turner RJ, Cui M. Physical limitations and depressive symptoms: Exploring the nature of the association. Journal of Gerontology: Social Sciences. 2008; 63B:S219-S228.

Goffman, E. Stigma: Notes on the management of spoiled identity. New York: Simon \& Schuster; 1963.

Hatzenbuehler ML. How does sexual minority stigma 'get under the skin'? A psychological mediation framework. Psychological Bulletin. 2009; 135(5):707-30. [PubMed: 19702379]

Hewitt PL, Flett GL, Ediger E. Perfectionism and depression: Longitudinal assessment of a specific vulnerability hypothesis. Journal of Abnormal Psychology. 1996; 105(2):276. [PubMed: 8723009]

Hollingshead, AB. Two factor index of social position. New Haven, CT: A.B. Hollingshead; 1957.

Hughes RB, Swedlund N, Petersen N, Nosek MA. Depression and women with spinal cord injury. Topics in Spinal Cord Injury Rehabilitation. 2001; 7:16-24.

Jacoby A. Felt versus enacted stigma: A concept revisited: Evidence from a study of people with epilepsy in remission. Social Science \& Medicine. 1994; 38(2):269-274. [PubMed: 8140453]

Joachim G, Acorn S. Living with chronic illness: The interface of stigma and normalization. Canadian Journal of Nursing Research. 2000; 32(3):37-48. [PubMed: 11928132]

Kaiser Public Opinion Spotlight. Americans' views of disability. Menlo Park, CA: Kaiser Family Foundation; 2004.

Karp, G. Life on wheels for the active wheelchair user. Sebastopol, CA: O'Reilly \& Associates; 1999. 
Kelley-Moore JA, Schumacher JG, Kahana E, Kahana B. When do older adults become "disabled"? Social and health antecedents of perceived disability in a panel study of the oldest old. Journal of health and social behavior. 2006; 47(2):126-141. [PubMed: 16821507]

Kessler RC, McLeod JD. Sex differences in vulnerability to undesirable life events. American Sociological Review. 1984; 49:620-631.

Link BG, Cullen FT, Struening E, Dohrenwend B. A modified labeling theory approach to mental disorders. American Sociological Review. 1989; 54:400-423.

Livingston JD, Boyd JE. Correlates and consequences of internalized stigma for people living with mental illness: A systematic review and meta-analysis. Social Science \& Medicine. 2010; 71(12): 2150-2161. [PubMed: 21051128]

Markowitz FE. The effects of stigma on the psychological well-being and life satisfaction of persons with mental illness. Journal of Health and Social Behavior. 1998:335-347. [PubMed: 9919855]

McArdle JH. Latent variable modeling of differences and changes with longitudinal data. Annual Review of Psychology. 2009; 60:577-605.

Meyer IH. Prejudice, social stress, and mental health in lesbian, gay, and bisexual populations: Conceptual issues and research evidence. Psychological Bulletin. 2003; 129(5):674-97. [PubMed: 12956539]

Meyer IH, Schwartz S, Frost DM. Social patterning of stress and coping: Does disadvantaged social statuses confer more stress and fewer coping resources? Social Science \& Medicine. 2008; 67:368-79. [PubMed: 18433961]

Miller, CT., Major, BM. Coping with stigma and prejudice. In: Heatherton, TF.Kleck Michelle, RE.Hebl, R., Hull, JG., editors. The social psychology of stigma. New York: The Guilford Press; 2000. p. 243-272.

Muthén, LK., Muthén, BO. Mplus user's guide: Statistical analysis with latent variables. 6. Los Angeles, CA: Muthén \& Muthén; 1998-2010.

Nosek MA, Hughes RB. Psychosocial issues of women with physical disabilities: The continuing gender debate. Rehabilitation Counseling. 2003; 46:224-233.

Nosek MA, Hughes RB, Robinson-Whelen S. The complex array of antecedents of depression in women with physical disabilities: Implications for clinicians. Disability and rehabilitation. 2008; 30(3):174-183. [PubMed: 17852240]

Pearlin LI. The sociological study of stress. Journal of Health and Social Behavior. 1989; 30:241-256. [PubMed: 2674272]

Pearlin LI, Menaghan EG, Lieberman MA, Mullan JT. The stress process. Journal of Health and Social Behavior. 1981; 22:337-356. [PubMed: 7320473]

Pearlin LI, Schooler C. The structure of coping. Journal of Health and Social Behavior. 1978; 19:2-21. [PubMed: 649936]

Preacher KJ, Rucker DD, Hayes AF. Addressing moderated mediation hypotheses: Theory, methods, and prescriptions. Multivariate Behavioral Research. 2007; 42:185-227. [PubMed: 26821081]

Radloff LS. The CES-D scale: A self-report depression scale for research in the general population. Applied Psychosocial Measurement. 1977; 1:385-401.

Reitzes DC, Mutran EJ. Self and health: Factors that encourage self-esteem and functional health. The Journals of Gerontology Series B: Psychological Sciences and Social Sciences. 2006; 61(1):S44S51.

Rohmer O, Louvet E. Describing persons with disability: Salience of disability, gender, and ethnicity. Rehabilitation Psychology. 2009; 54:76-82. [PubMed: 19618706]

Rosenberg, M. Conceiving the self, second edition. Melbourne, FL: Academic Press; 1986.

Seeman TE, Berkman LF, Charpentier PA, Blazer DG, Albert MS, Tinetti ME. Behavioral and psychosocial predictors of physical performance: MacArthur studies of successful aging. Journal of Gerontology: Medical Sciences. 1995; 50A:M177-M183.

Sirey JA, Bruce ML, Alexopoulos GS, Perlick DA, Friedman SJ, Meyers BS. Stigma as a barrier to recovery: Perceived stigma and patient-rated severity of illness as predictors of antidepressant drug adherence. Psychiatric Services. 2001; 52:1615-1620. [PubMed: 11726752] 
Steinmetz, E. Americans with disabilities: 2002, Current population reports, P70-107. Washington, DC: U.S. Census Bureau; 2006.

Stuck AE, Walthert JM, Nikolaus T, Büla CJ, Hohmann C, Beck JC. Risk factors for functional status decline in community-living elderly people: A systematic literature review. Social Science \& Medicine. 1999; 48(4):445-469. [PubMed: 10075171]

Susman J. Disability, stigma and deviance. Social Science \& Medicine. 1994; 38(1):15-22. [PubMed: 8146705]

Taylor MG, Lynch SM. Trajectories of impairment, social support and depressive symptoms in later life. Journal of Gerontology: Social Sciences. 2004; 59B:S238-246.

Thorne S, Paterson B. Shifting images of chronic illness. Image: Journal of Nursing Scholarship. 1998; 30(2):173-178.

Turner RJ, Avison WR. Status variations in stress exposure: Implications for the interpretation of research on race, socioeconomic status and gender. Journal of Health and Social Behavior. 2003; 44:488-505. [PubMed: 15038145]

Turner RJ, Lloyd DA, Taylor J. Physical disability and mental health: An epidemiology of psychiatric and substance disorders. Rehabilitation Psychology. 2006; 51(3):214-223.

Turner RJ, Noh S. Physical disability and depression: A longitudinal analysis. Journal of Health and Social Behavior. 1988; 29(1):23-37. [PubMed: 2966841]

Warner DF, Adams SA. Widening the social context of disablement among married older adults: Considering the role of nonmarital relationships for loneliness. Social Science Research. 2012; 41(6):1529-1545. [PubMed: 23017972]

Wheaton, B. Sampling the stress universe. In: Avison, WR., Gotlib, IH., editors. Stress and Mental Health: Contemporary Issues and Prospects for the Future. New York: Plenum Press; 1994. p. 77-114.

Williams DR, Yu Y, Jackson JS, Anderson NB. Racial differences in physical and mental health: Socioeconomic status, stress and discrimination. Journal of Health Psychology. 1997; 2:335-351. [PubMed: 22013026]

World Health Organization. International classification of functioning, disability, and health (ICF). Geneva: World Health Organization; 2001.

Yang Y. How does functional disability affect depressive symptoms in late life? The role of perceived support and psychological resources. Journal of Health and Social Behavior. 2006; 47(4):355-372. [PubMed: 17240925]

Zitzelsberger H. (In) visibility: Accounts of embodiment of women with physical disabilities and differences. Disability \& Society. 2005; 20(4):389-403. 


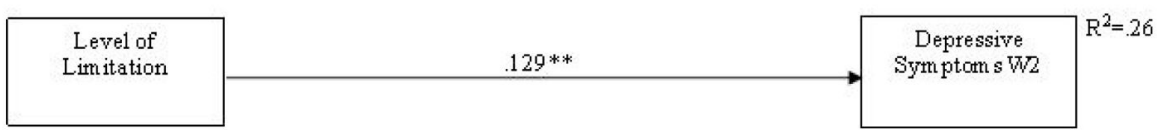

FIGURE 1. Structural Equation Model of W2 Depressive Symptoms on W1 Functional Limitation, Perceived Stigma and Other Stressor Exposure, and Coping Resources $(\mathrm{N}=417)$ Notes: Standardized regression coefficients reported. * significant at .05; ** significant at . 01; *** significant at .001. Model controls for age, gender, socioeconomic status, race/ ethnicity and depressive symptoms at W1. 


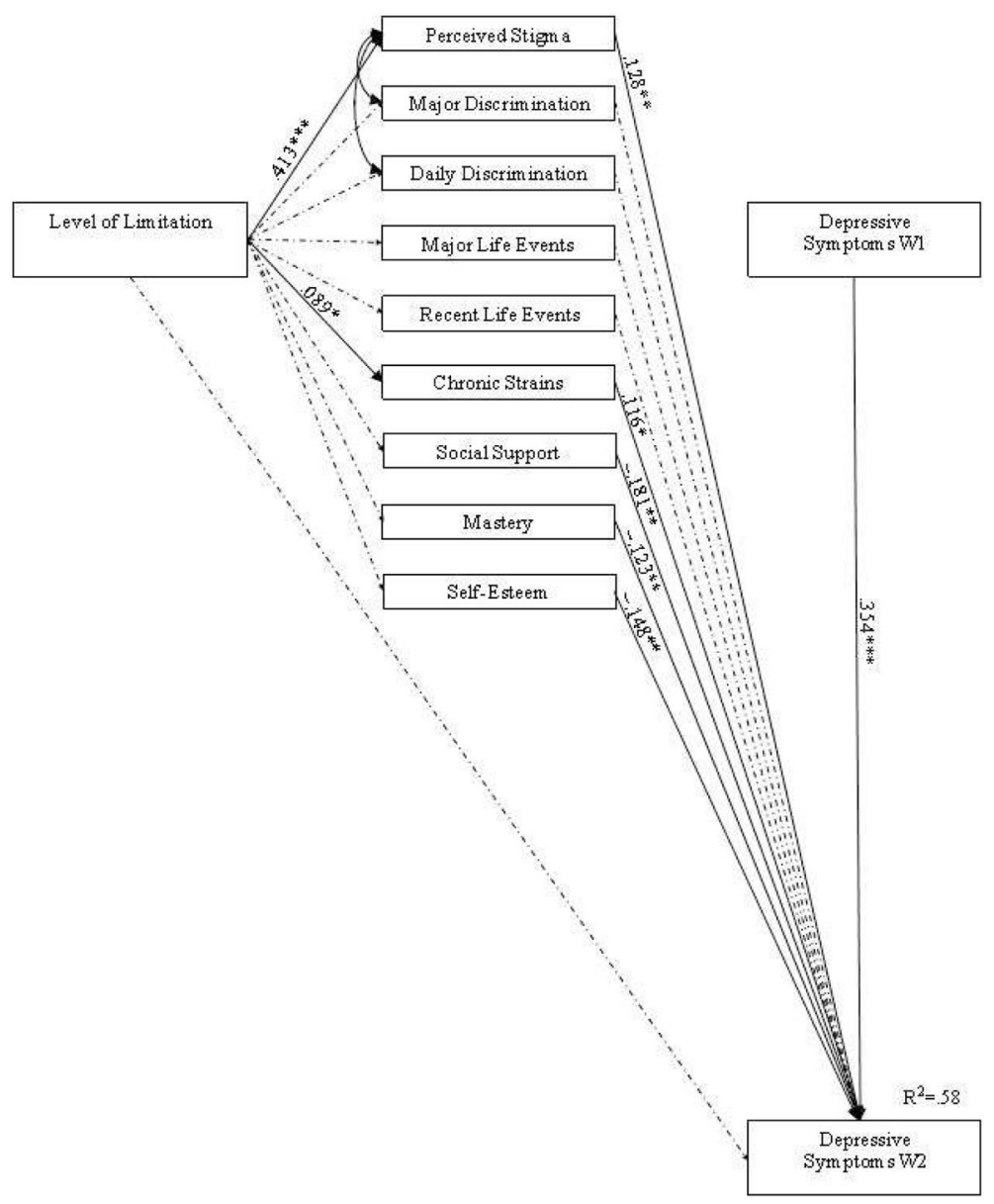

FIGURE 2. Structural Equation Model of W2 Depressive Symptoms on W1 Functional Limitation, Perceived Stigma and Other Stressor Exposure, and Coping Resources $(\mathbf{N}=417)$ Notes: Standardized regression coefficients reported. A solid arrow indicates a significant effect; a dashed arrow indicates a non-significant effect; * significant at .05; ** significant at .01; *** significant at .001. Model controls for age, gender, socioeconomic status and race/ethnicity. Model covariance of perceived stigma and daily discrimination is .357 ( $\mathrm{p}<$. 001); model covariance of perceived stigma and major discrimination is .275 ( $\mathrm{p}<.001)$. 
TABLE 1

Distribution of Primary Disabling Conditions (W1)

\begin{tabular}{|c|c|c|}
\hline Condition & Frequency & $\%$ \\
\hline $\begin{array}{l}\text { Heart diseases including rheumatic fever, acute myocardial infarction, subacute and chronic ischemic heart disease, } \\
\text { pulmonary heart disease, others }\end{array}$ & 27 & 6.4 \\
\hline Osteoarthritis (other than spine) & 9 & 2.3 \\
\hline Osteoarthritis of spine, degenerative disk disease & 14 & 3.4 \\
\hline Rheumatoid arthritis & 15 & 3.6 \\
\hline Arthritis (other) & 46 & 11.0 \\
\hline Spinal cord, multiple sclerosis, peripheral nerve disorders, polio, primary muscle disease & 15 & 3.6 \\
\hline Back pain, including back problems and whiplash & 31 & 7.4 \\
\hline Cerebrovascular diseases including stroke, brain aneurysm, brain hemorrhage & 21 & 5.1 \\
\hline Brain substance including Parkinsonism, cerebral palsy, post-head injury & 40 & 9.6 \\
\hline Asthma & 7 & 1.7 \\
\hline Emphysema and chronic obstructive pulmonary disease & 15 & 3.6 \\
\hline Blindness - complete and partial & 11 & 2.6 \\
\hline Hearing impairment & 3 & 0.8 \\
\hline Diabetes Mellitus & 45 & 10.8 \\
\hline Acquired deformities of the spine - scoliosis, fusion of the spine & 6 & 1.4 \\
\hline Musculoskeletal injury, including amputation & 45 & 10.8 \\
\hline Metabolic disease, organ disease (other than heart) & 12 & 2.8 \\
\hline Cancer & 15 & 3.6 \\
\hline HIV, hepatitis, other infectious disease & 10 & 2.3 \\
\hline Congenital deformity (not otherwise classified) & 4 & 1.0 \\
\hline Other & 26 & 6.2 \\
\hline Total & 417 & 100.0 \\
\hline
\end{tabular}


TABLE 2

Means and Standard Deviations of Variables $(\mathrm{N}=417)$

\begin{tabular}{|c|c|c|c|}
\hline Characteristics & Range & Mean & Standard Deviation \\
\hline \multicolumn{4}{|l|}{ Depressive Symptoms } \\
\hline $\mathrm{W} 1$ & $3-48$ & 13.954 & 7.761 \\
\hline $\mathrm{W} 2$ & $0-44$ & 13.981 & 7.918 \\
\hline Functional Limitation & $5-80$ & 36.503 & 14.568 \\
\hline Perceived Stigma & $0-35$ & 10.710 & 5.181 \\
\hline Major Discrimination & $0-6$ & 1.185 & .722 \\
\hline Day-to-Day Discrimination & $0-40$ & 4.423 & 6.351 \\
\hline Major Life Events & $0-23$ & 10.016 & 3.764 \\
\hline Recent Life Events & $0-8$ & .917 & 1.430 \\
\hline Chronic Strains & $0-40$ & 6.363 & 7.782 \\
\hline Social Support & $0-64$ & 53.745 & 11.227 \\
\hline Mastery & $7-35$ & 23.765 & 6.546 \\
\hline Self-Esteem & $6-30$ & 27.161 & 3.643 \\
\hline Age & $20-93$ & 59.787 & 15.191 \\
\hline Sex ( $\%$ female $)$ & 0,1 & 56.5 & - \\
\hline Socioeconomic Status & $.667-14$ & 6.372 & 2.486 \\
\hline \multicolumn{4}{|l|}{ Race/ethnicity (\%) } \\
\hline Non-Hispanic White & 0,1 & 23.50 & - \\
\hline African American & 0,1 & 39.33 & - \\
\hline Cuban & 0,1 & 21.10 & - \\
\hline Non-Cuban Hispanic & 0,1 & 16.07 & \\
\hline
\end{tabular}

Note: Values reported at W1 except where noted. 


\section{롤 \\ 골}

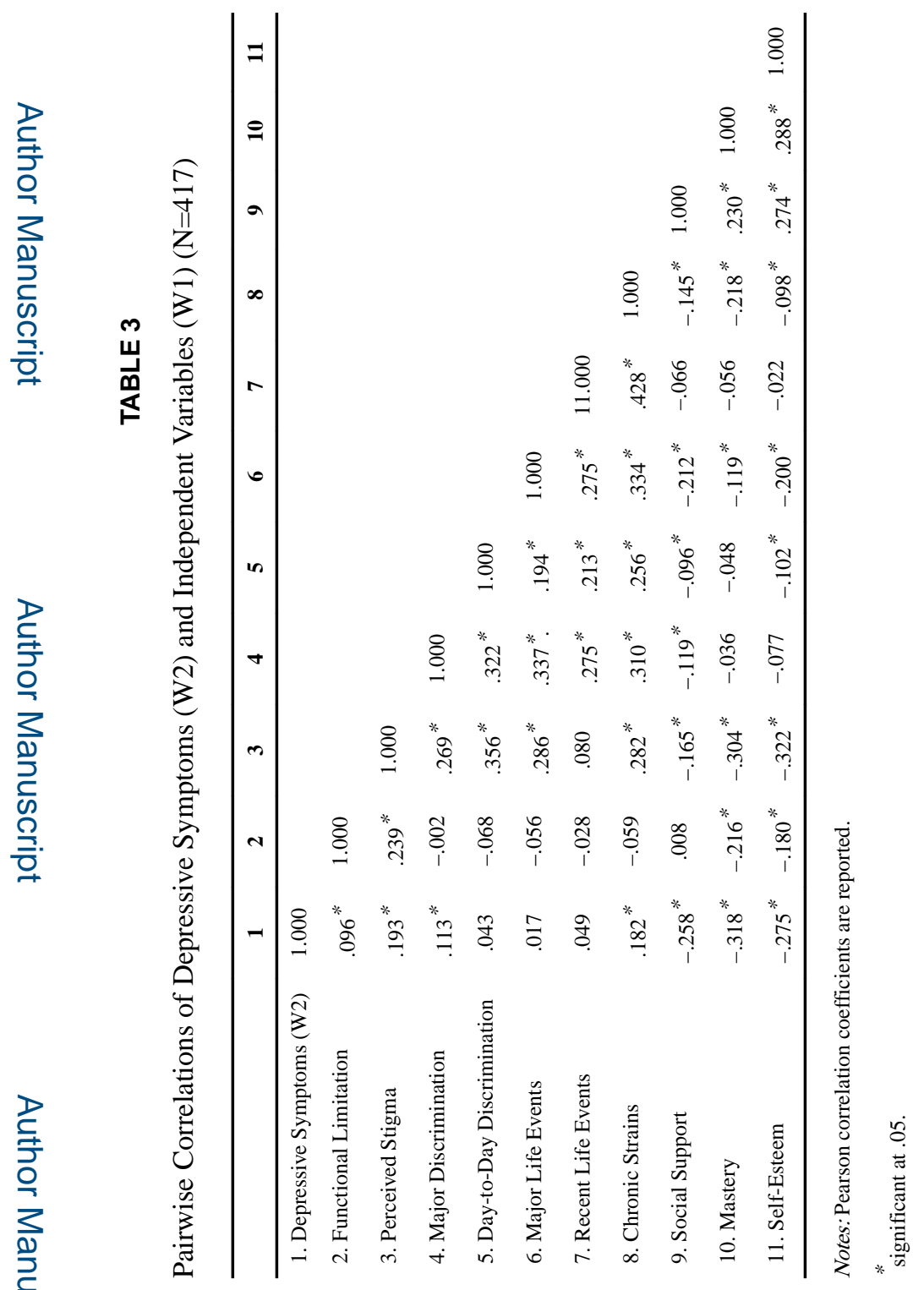

Soc Sci Res. Author manuscript; available in PMC 2018 February 01. 